\title{
PERSPECTIVA DAS PESQUISAS EM CIÊNCIA DA INFORMAÇÃO NO BRASIL SOBRE MÍDIAS SOCIAIS E POLIITICAS
}

\author{
PERSPECTIVE OF BRAZILIAN RESEARCH IN \\ INFORMATION SCIENCE ON SOCIAL MEDIA AND \\ POLITICS
}

\author{
Angela Maria Grossi de Carvalhoa \\ Maira Nani Françab \\ Gabriel Henrique de Oliveira Lopesc
}

\begin{abstract}
RESUMO
Introdução: A compreensão dos fenômenos políticos e das redes sociais (laços) nas mídias sociais permite refletir sobre as formas com que os atores se conectam, influenciam e se relacionam na sociedade contemporânea. Objetivo: Identificar as contribuições das pesquisas da Ciência da Informação sobre mídias sociais e políticas, desde a concepção de política pública, até a ação social voltada à política. Metodologia: Os documentos recuperados foram submetidos à análise bibliométrica e cronológica do conteúdo associado com fatos que marcaram a história no Brasil e no mundo. Resultados: As produções científicas da Ciência da Informação no domínio analisado têm sido desenvolvidas desde 2007, com uma elite de pesquisadores e uma comunidade epistêmica em formação. O período de maior produtividade foi 2014, com discussões sobre o papel das mídias sociais na organização de mobilizações, manifestações, participação política, governo eletrônico e políticas públicas, contribuindo para o delineamento temático da área, o acompanhamento de sua evolução e seu âmbito de aplicação. Conclusões: Nos últimos dez anos, observou-se um crescimento considerável da produção científica da Ciência da Informação na imbricação dos campos informacional, tecnológico e político, dada sua complexidade e relevância.
\end{abstract}

\footnotetext{
1 Pesquisa desenvolvida na linha Gestão, Políticas e Economia da Informação e Comunicação do Laboratório de Estudos em Comunicação, Tecnologia e Educação Cidadã (LECOTEC), vinculado à Faculdade de Arquitetura, Artes e Comunicação (FAAC) da Unesp como parte integrante do Projeto Cartografias digitais: informação, redes e inteligência coletiva (Unesp).

a Doutora em Ciência da Informação pela Universidade Estadual Paulista Júlio de Mesquita Filho (UNESP). Docente do Programa de Pós-Graduação em Ciência da Informação da Universidade Estadual Paulista Júlio de Mesquita Filho (UNESP). E-mail: angela.grossi@unesp.br.

b Doutoranda do Programa de Pós-Graduação em Ciência da Informação (PPGCI) da Universidade Estadual Paulista Júlio de Mesquita Filho (UNESP). Bibliotecária-Documentalista da Universidade Federal de Uberlândia E-mail: mairanani@hotmail.com.

c Mestrando do Programa de Pós-Graduação em Ciência da Informação da Universidade Estadual Paulista Júlio de Mesquita Filho (UNESP). E-mail: oliveira.gabriel92@gmail.com.
} 
Descritores: Rede social. Mídias sociais. Políticas de informação. Direito à informação. Acesso à informação pública.

\section{INTRODUÇÃO}

A popularização das mídias sociais e a ampliação de seus usos foram responsáveis por um conjunto de mudanças que sensibilizaram os campos científico - na pesquisa de ambientes de informação digital e tecnológico - e político - no relacionamento dos usuários entre si e com as instituições, partidos ou ideologias -, em torno de uma nova sociabilidade. Oliveira (2012) afirma que as mídias sociais e seus desenvolvimentos franquearam novas formas de participação política independentemente das estruturas políticas tradicionais e das estratégias comunicacionais empreendidas pela comunicação de massa. Corroborando essa ideia, Martino (2014, p. 114) assinala que a participação política nas redes digitais abre precedente "para se pensar na noção de democracia e sua relação com a circulação de informação e a produção de conhecimento".

As mídias sociais, segundo Fuchs (2015/2016), têm potencial de se tornarem esfera pública - teoria habermasiana - e darem vida à ação comunicativa. Todavia, o autor pondera sobre os fatores limitantes dessa possibilidade, ao destacar que a mídia é direcionada pelos poderes políticos e do capital: as mídias sociais são "controlada por empresas e pelo estado, os quais colonizam e, assim, destroem os [seus] potenciais de esfera pública [...]" (FUCHS, 2015, p. 58).

No âmbito da Ciência da Informação $(\mathrm{Cl})$, o desenvolvimento de pesquisas acerca das mídias sociais e de seus impactos, sobretudo a partir dos anos 2010, possibilitou a emergência de novos olhares sobre o fenômeno informacional aliado à política e às redes digitais. Contudo, por se tratar de um objeto cuja evolução é contínua, o estudo das mídias sociais apresenta diversidade quanto às definições, nomenclaturas, descrições, metodologias e abordagens.

Acioli (2007) identifica três abordagens, aplicadas no campo da antropologia, acerca da noção de redes e redes sociais: a) metafórica: voltada à 
filosofia da rede ou aproximação conceitual; b) analítica: que enfoca a metodologia de análise de redes; e c) tecnológica: centrada nas redes de conexões e possibilidades relacionadas às interações sociais por meio de redes informacionais, eletrônicas e interorganizacionais. Nesta pesquisa adotou-se a abordagem tecnológica, uma vez que ambientes de informação digitais voltados para a participação, a colaboração e a interação, como o extinto Orkut, o Facebook e o Twitter, nos últimos dez anos têm sido, comumente, nomeados na Ciência da Informação de redes sociais.

Em levantamento realizado entre as produções científicas analisadas no presente estudo, percebeu-se que a maioria delas nomeia seu objeto como redes sociais; e as demais como redes sociais virtuais; sites de redes sociais; redes sociais on-line; rede social na internet, redes sociais da web, redes sociais móveis e, com maior ocorrência nos últimos anos, mídias sociais. Assim, este estudo opta pelo termo mídias sociais, compreendido como um conjunto de aplicativos na internet desenvolvidos a partir da estrutura ideológica e tecnológica da Web 2.0 e que permite a interação social por meio do compartilhamento de conteúdo nos diversos formatos, gerado pelo usuário (ARAÚJO, 2016; KAPLAN; HAENLEIN, 2010), enquanto redes sociais se restringe "a grupos de pessoas que possuem e compartilham interesses comuns e/ou relacionamentos" (ARAÚJO, 2016, p. 7), dentro e fora do mundo virtual. Destaca-se ainda que esse termo tem sido empregado com maior ênfase na produção científica da Ciência da Informação desde 2013, com crescimento acentuado em 2017.

A partir da contextualização, busca-se, com este estudo, conhecer as contribuições das pesquisas realizadas no Brasil, na interseção dos domínios mídias sociais e políticas, com base no recorte da produção científica no campo da Ciência da Informação, prenunciando relevância da temática no contexto da sociedade contemporânea.

\section{PROCEDIMENTOS METODOLÓGICOS}

Este estudo de natureza qualitativa consiste em uma pesquisa exploratória quanto aos objetivos e bibliográfica, quanto aos procedimentos 
técnicos (SILVA; MENEZES, 2005), para investigar o domínio políticas e mídias sociais, objeto de análise.

O levantamento de dados foi realizado na Base de Dados em Ciência da Informação (BRAPCl), na segunda quinzena de fevereiro de 2018, a partir dos descritores: rede social, mídia social, política e suas variações no plural, considerando o período de 1972 a 2018 como delimitação temporal. Não foram considerados os trabalhos com títulos repetidos, nem resenhas, editoriais, documento (dossiê de evento), nem entrevistas, nem aqueles cujo assunto não era pertinente à temática central da pesquisa.

Com base na análise do título, resumo, palavras-chave e objeto de pesquisa de cada documento e na aplicação dos critérios de exclusão, acima descritos, dos 156 documentos recuperados, obteve-se um total de 38 documentos (Apêndice A), elaborados por 77 autores, englobando artigos científicos, artigos científicos temáticos, relato de experiência (comunicação de pesquisa), trabalhos de conclusão de curso, comunicação, trabalhos publicados em anais de evento e artigos de opinião.

Após essa primeira etapa de organização do conhecimento, o conteúdo da produção científica selecionada foi classificado a partir do Plano Geral de Classificação do Tesauro Brasileiro de Ciência da Informação (PINHEIRO; FERREZ, 2014, p. 18-19), publicado pelo Instituto Brasileiro de Informação em Ciência e Tecnologia (IBICT). Os trabalhos recuperados foram ordenados pelos seguintes assuntos: usos e usuários da informação; serviços de informação; direito à informação e propriedade intelectual; políticas e ações de informação; e sociedade da informação - conforme apresentado na primeira coluna do Quadro 1.

$\mathrm{Na}$ etapa posterior, propôs-se a subdivisão dessa classificação em catorze categorias (Quadro 1, coluna 2), algumas delas extraídas do próprio Tesauro (vocabulário controlado), e outras que receberam o status de vocabulário livre por não estarem contempladas no referido instrumento de representação do conhecimento na $\mathrm{Cl}$. Como categorias integrantes do grupo vocabulário controlado, elencaram-se: comportamento do usuário; governo eletrônico; direito à privacidade; segurança da informação; ética na informação; 
inclusão social; políticas públicas; políticas de informação; e redes sociais. E do grupo vocabulário livre: políticas institucionais; participação política; mobilização; movimento social; e manifestações. Para elucidar determinados conceitos e demonstrar a sua abrangência, no Quadro 1, também são apresentados o escopo de cada categoria e os respectivos documentos agrupados por similaridade temática.

A Ciência da Informação, como uma ciência recente, de natureza interdisciplinar, possibilita a identificação constante de novas estruturas e termos que representem a organização do conhecimento neste campo. Considerando a complexidade das questões políticas imbricadas com as informacionais e tecnológicas, além das categorias livres criadas, citadas anteriormente, observouse que outras novas categorias poderiam ser suscitadas neste contexto, como Ativismo. Para exemplificar, destaca-se que a compatibilidade de um trabalho em mais de uma categoria foi identificada nos trabalhos de Radomsky e Solagna (2016) e Rothberg, Luvizotto e Vanzini (2014), categorizados em políticas públicas; Morigi et al. (2015), classificado em mobilização; e Mendonça Júnior, Rodrigues e Tavares (2015) e Silva (2013), categorizados em comportamento do usuário, que também poderiam ser incluídos na categoria livre ativismo, por abordarem o uso das mídias sociais na criação e organização de discussões e pautas de reivindicação sobre assuntos de interesses coletivos; no entanto, essa categoria não foi contemplada neste estudo. 


\section{Quadro 1 - Organização do conhecimento no domínio mídias sociais e políticas em categorias}

\begin{tabular}{|c|c|c|c|}
\hline Classificação & Categorias & Escopo & Documentos selecionados \\
\hline $\begin{array}{l}\text { Usuários e usos } \\
\text { da informação }\end{array}$ & $\begin{array}{l}\text { Comportamento } \\
\text { do usuário* }\end{array}$ & $\begin{array}{l}\text { Compreende o procedimento de um indivíduo frente a estímulos sociais ou } \\
\text { sentimentos dos usuários nas mídias sociais em relação a temas de ambiência } \\
\text { política. }\end{array}$ & $\begin{array}{l}\text { Brito et al. (2015), Mendonça } \\
\text { Júnior, Rodrigues e Tavares } \\
\text { (2015), Morigi et al. (2015) e } \\
\text { Silva (2013). }\end{array}$ \\
\hline $\begin{array}{l}\text { Serviços de } \\
\text { informação }\end{array}$ & $\begin{array}{l}\text { Governo } \\
\text { eletrônico* }\end{array}$ & $\begin{array}{l}\text { Trata-se dos serviços informacionais na internet oferecidos pelos três níveis de } \\
\text { governo e que servem à população. }\end{array}$ & $\begin{array}{l}\text { Cordeiro et al. (2012) e } \\
\text { Sampaio et al. (2014). }\end{array}$ \\
\hline \multirow{2}{*}{$\begin{array}{l}\text { Direito à } \\
\text { informação e } \\
\text { propriedade } \\
\text { intelectual }\end{array}$} & $\begin{array}{l}\text { Direito à } \\
\text { privacidade* }\end{array}$ & $\begin{array}{l}\text { Refere-se à liberdade de decisão sobre como revelar ou ocultar informações a } \\
\text { terceiros. }\end{array}$ & Assumpção e Sant'Ana (2015). \\
\hline & $\begin{array}{l}\text { Segurança da } \\
\text { informação* }\end{array}$ & $\begin{array}{l}\text { Relaciona a "proteção e preservação da informação, e tem por finalidade evitar } \\
\text { alterações, intencionais ou não, nos seus atributos de confidencialidade, } \\
\text { integridade, disponibilidade e autenticidade" (PINHEIRO; FERREZ, 2014, p. 200). }\end{array}$ & $\begin{array}{l}\text { Silva, Araújo e Azevedo (2013a, } \\
\text { 2013b). }\end{array}$ \\
\hline \multirow{5}{*}{$\begin{array}{l}\text { Políticas e } \\
\text { ações de } \\
\text { informação }\end{array}$} & $\begin{array}{l}\text { Ética na } \\
\text { informação* }\end{array}$ & $\begin{array}{l}\text { Destina-se às relações entre organização, disseminação, produção e uso da } \\
\text { informação articuladas nas dimensões éticas e códigos morais que regem a } \\
\text { sociedade }\end{array}$ & Bezerra e Araújo $(2008,2011)$. \\
\hline & Inclusão social* & $\begin{array}{l}\text { Preocupa-se em denunciar, investigar, analisar ou refletir sobre o processo de } \\
\text { recuperação da dignidade por parte dos excluídos sociais, através da } \\
\text { participação ou de ações coletivas. }\end{array}$ & $\begin{array}{l}\text { Ribas e Ziviani (2007) e } \\
\text { Roso e Silva (2017). }\end{array}$ \\
\hline & Políticas públicas* & $\begin{array}{l}\text { Mantêm relação com o conjunto de políticas governamentais que formam a } \\
\text { legislação do país no campo da informação. }\end{array}$ & $\begin{array}{c}\text { Jesus, Simeão e Martins (2016), } \\
\text { Radomsky e Solagna (2016) e } \\
\text { Rothberg, Luvizotto e Vanzini } \\
\text { (2014). }\end{array}$ \\
\hline & $\begin{array}{l}\text { Políticas de } \\
\text { informação* }\end{array}$ & $\begin{array}{l}\text { Refere-se às ações, por parte de diversos organismos e instâncias de governo, } \\
\text { visando à implementação de mecanismos que se relacionem à coleta, à } \\
\text { disseminação, ao armazenamento, ao tratamento e ao descarte da informação, } \\
\text { tendo como horizonte potencializar fluidez de circulação, consumo e produção de } \\
\text { informação. }\end{array}$ & Moreira e Pinheiro (2015). \\
\hline & $\begin{array}{c}\text { Políticas } \\
\text { institucionais }\end{array}$ & $\begin{array}{l}\text { Trata-se da análise, reflexão ou implementação de políticas de informação em ou } \\
\text { para instituições sociais, públicas ou privadas. }\end{array}$ & Corgosinho e Monteiro (2013). \\
\hline
\end{tabular}

Inf. Inf., Londrina, v. 24, n. 3, p. $260-288$, set./dez. 2019. 


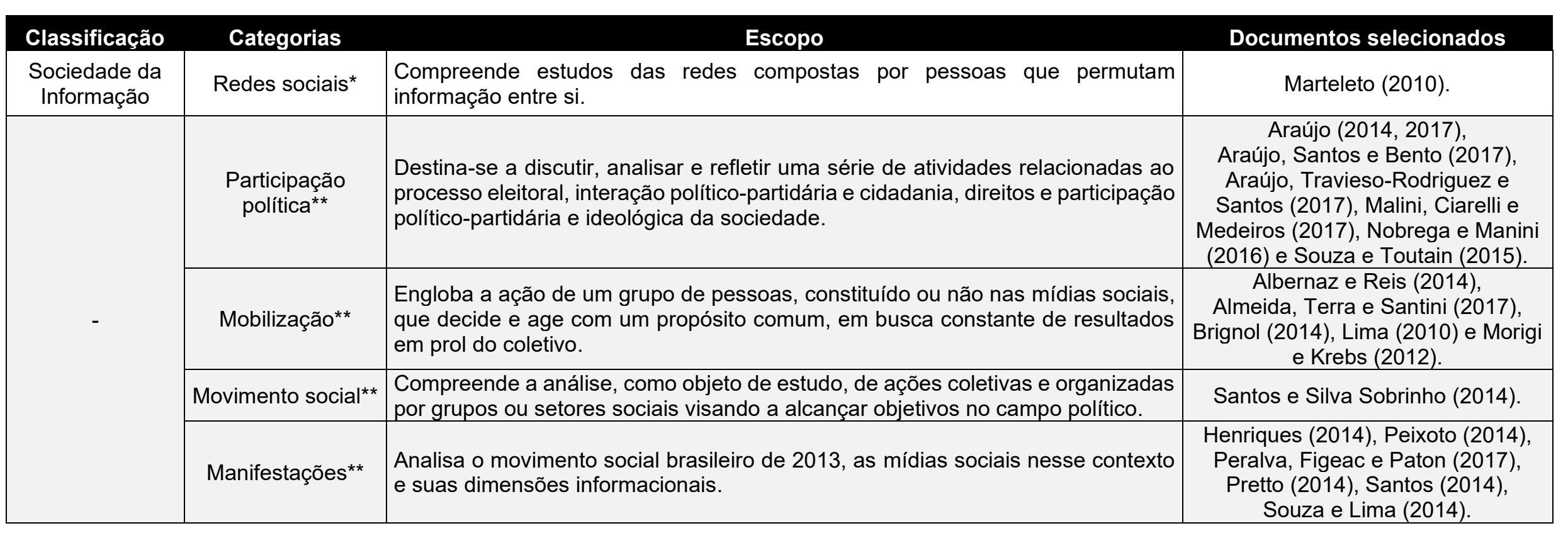

Fonte: elaborado a partir de classificação proposta por Pinheiro e Ferrez (2014).

$$
\text { * vocabulário controlado }
$$


O contexto teórico baseado em estudos sobre ativismo digital e movimentos sociais em que o artigo de Rothberg, Luvizotto e Vanzini (2014) foi elaborado e o cenário das manifestações de 2013 em que o objeto de pesquisa foi discutido reforçaram sua correspondência com outras categorias de análise afins.

A fim de identificar a construção e socialização do conhecimento científico no domínio proposto, foi realizado um estudo bibliométrico com os autores citados. Para cada um dos 38 documentos selecionados, foram consideradas todas as referências que apresentavam, no campo "Autoria", entrada de autores pessoais, com ou sem indicação de responsabilidade de conjunto da obra, incluindo as referências com mais de três autores que adotaram a expressão et al.

Também se consideraram as autocitações; no entanto, não foram contabilizadas para indicação da comunidade epistêmica na temática pesquisada. Dos 706 pesquisadores referenciados, 613 (86,8\%) foram citados apenas uma vez. Para a seleção dos pesquisadores mais citados, aplicou-se a Lei do Elitismo, em que a raiz quadrada do número total de contribuintes em um determinado domínio representa a elite da área estudada (URBIZAGÁSTEGUI ALVARADO, 2009). Procedimento semelhante foi aplicado para identificação da elite dos autores citantes no domínio analisado. Ao aplicar essa lei, por aproximação, foram considerados 36 autores mais citados em pelo menos três trabalhos.

\section{RESULTADOS E DISCUSSÕES}

Esta seção está organizada em duas partes: a) análise bibliométrica da produção científica (autores citantes e citados; fontes de publicação; cobertura temporal; produção por categoria e produção por ano/categoria); e b) análise do conteúdo, de forma cronológica, associando fatos que marcaram a história no Brasil e no mundo, no âmbito do domínio analisado, com o conteúdo dos documentos selecionados, a partir do encadeamento entre as categorias. 


\subsection{ANÁlise Bibliométrica dAs PROduções}

Dos 77 autores citantes, destacam-se o professor da Ciência da Informação Ronaldo Araújo, autor de quatro trabalhos, além de outros oito autores - Eliany Araújo, Wagner Araújo, Patrícia Azevedo, Marcos Antônio Bezerra, Wagner Martins, Valdir José Morigi, Sarah Rubia Santos e Narjara Bárbara Silva -, com dois trabalhos cada. Os demais autores publicaram apenas um trabalho sobre a temática analisada.

O Quadro 2 apresenta, dentre os 706 autores citados, os 36 mencionados em pelo menos três dos 38 documentos analisados. Os pesquisadores citados em mais trabalhos foram o sociólogo espanhol Manuel Castells (16), a jornalista brasileira Raquel Recuero (11) e a bibliotecária, também do Brasil, Regina Marteleto (7). Salienta-se que dados semelhantes foram identificados na pesquisa de França, Carvalho e Grácio (2018).

\section{Quadro 2 - Autores citados em pelo menos três trabalhos}

\begin{tabular}{|l|l|l|}
\hline CASTELLS, M. (BRA), 16 & ALVES, C. B. (BRA), 3 & MARQUES, F. P. J. (BRA), 3 \\
\hline RECUERO, R. (BRA), 11 & ANTOUN, H. (BRA), 3 & MASSUCHIN, M. G. (BRA), 3 \\
\hline MARTELETO, R. M. (BRA), 7 & ARAÚJO, W. J. de. (BRA), 3 & MITNICK, K. D. (USA), 3 \\
\hline LÉVY, P. (TUN), 6 & ASSMANN, S. J. (BRA), 3 & PEIXOTO, M. C. P. (BRA), 3 \\
\hline AGGIO, C (BRA), 4 & BAUMAN, Z. (POL), 3 & PRIMO, A. (BRA), 3 \\
\hline AMARAL, A. (BRA), 4 & BOBBIO, N. (ITA), 3 & REIS, L. do S. (BRA), 3 \\
\hline ARAUJO, R. F. (BRA), 4 & BOURDIEU, P. (FRA), 3 & SAMPAIO, R. C. (BRA), 3 \\
\hline BOYD, D. (USA), 4 & CAVALCANTI JR., R. L. (BRA), 3 & SCHERER-WARREN, I. (BRA), 3 \\
\hline CAPURRO, R. (URY), 4 & HALL, S. (JAM), 3 & SIMON, W. L. (BRA), 3 \\
\hline FRAGOSO, S. (BRA), 4 & HJORLAND, B. (DNK), 3 & STASSUN, C. C. S. (BRA), 3 \\
\hline LATOUR, B. (FRA), 4 & LEMOS, A. (BRA), 3 & TOURAINE, A. (FRA), 3 \\
\hline MALINI, F. (BRA), 4 & LENNERT, L. S. (BRA), 3 & ŽIŽEK, S. (SVN), 3 \\
\hline
\end{tabular}

Fonte: Os autores.

Dos autores citados, com pelo menos uma formação na Ciência da Informação (graduação, lato sensu, stricto sensu, pesquisador), salientam-se Regina Marteleto (7), Pierre Lévy (6), Raphael Capurro (4), Ronaldo Araújo (4), Wagner Araújo (3) e Birger Hjørland (3). Outro resultado similar ao de França, Carvalho e Grácio (2018) identificado neste estudo foi o exíguo aporte conceitual nos teóricos da Ciência da Informação, com destaque para Raphael Capurro e 
Birger Hjørland (Quadro 2). Gernot Wersig e Ulrich Neveling também foram citados, porém com a aplicação da Lei do Elitismo não foram ranqueados como autores mais citados.

Ratificando a natureza interdisciplinar da Ciência da Informação, também foram identificados autores com formação na área de Ciências Sociais Aplicadas (Comunicação Social, Desenho Industrial); Ciências Humanas (Antropologia, Filosofia, História, Psicologia, Sociologia, Teologia); e Ciências Exatas e da Terra (Ciência da Computação). Ressalta-se ainda que apenas sete trabalhos analisados $(18,4 \%)$ não mencionaram nenhum dos pesquisadores considerados como núcleo da literatura científica no domínio mídias sociais e políticas, o que reforça a visibilidade e o reconhecimento do grupo de autores listados no Quadro 2.

Ao confrontar os autores citantes (77) dos documentos analisados com os 36 autores mais citados, percebe-se o estágio inicial de desenvolvimento da comunidade epistêmica nesta temática emergente na Ciência da Informação. Dentre os especialistas que publicam sobre mídias sociais e políticas e que ao mesmo tempo são citados por outros pesquisadores, destacam-se: Regina Marteleto, referida em seis trabalhos; Fábio Malini, citado em três, e Wagner Araújo, em um¹.

Conforme apresentado no Gráfico 1, verifica-se que os assuntos mais discutidos nos trabalhos analisados foram: participação política $(18,4 \%)$; manifestações (15,7\%); e, na sequência, mobilização (13,1\%).

O cruzamento dos dados dos autores mais citados com as categorias mais discutidas mostra que os trabalhos sobre participação política utilizam como aporte teórico autores como a jornalista Raquel Recuero e os professores Camilo Aggio, Adriana Amaral e Suely Fragoso. Nos trabalhos sobre manifestações sobressaem os sociólogos Manuel Castells e Zigmunt Bauman e, nos de mobilização, evidenciam-se os sociólogos Manuel Castells, Pierre Lévy, Alain Touraine e os professores Fábio Malini e Henrique Antoun. Os teóricos da Ciência da Informação foram citados nos documentos pertencentes às categorias ética da informação (Capurro; Hjørland; Wersig e Neveling), políticas

\footnotetext{
${ }^{1}$ As autocitações não foram consideradas.
} 
públicas (Capurro e Hjørland) e inclusão social (Wersig e Neveling).

\section{Gráfico 1 - Produção por categoria}

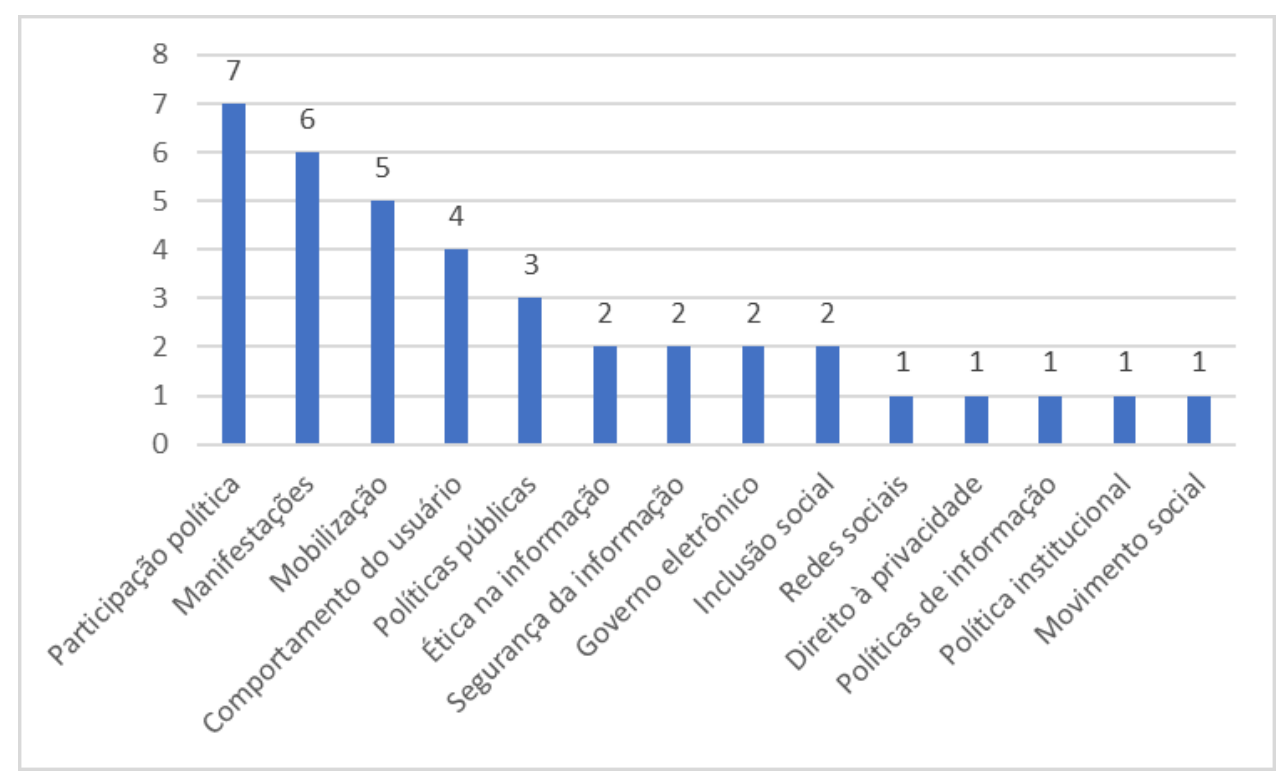

Fonte: Elaborado pelos autores.

Em maio de 2014, a Liinc em Revista, em comemoração aos seus dez anos, publicou o número temático Redes, ruas, mídias: revolta e reação, o que contribuiu para que a Liinc fosse o periódico com o maior número de artigos publicados sobre a temática analisada (Gráfico 2). Por outro lado, independentemente desse resultado, a Liinc (Qualis B1) destaca-se ao lado de outros periódicos da área que publicam sobre o domínio mídias sociais e políticas, como a Informação \& Sociedade (Qualis A1) e a Comunicação \& Informação (Qualis B2), além do principal fórum nacional de debates e reflexões que reúne pesquisadores interessados em temas especializados da Ciência da Informação, o Encontro Nacional de Pesquisa em Ciência da Informação (Enancib) (Gráfico 2). 


\section{Gráfico 2 - Fonte de publicação}

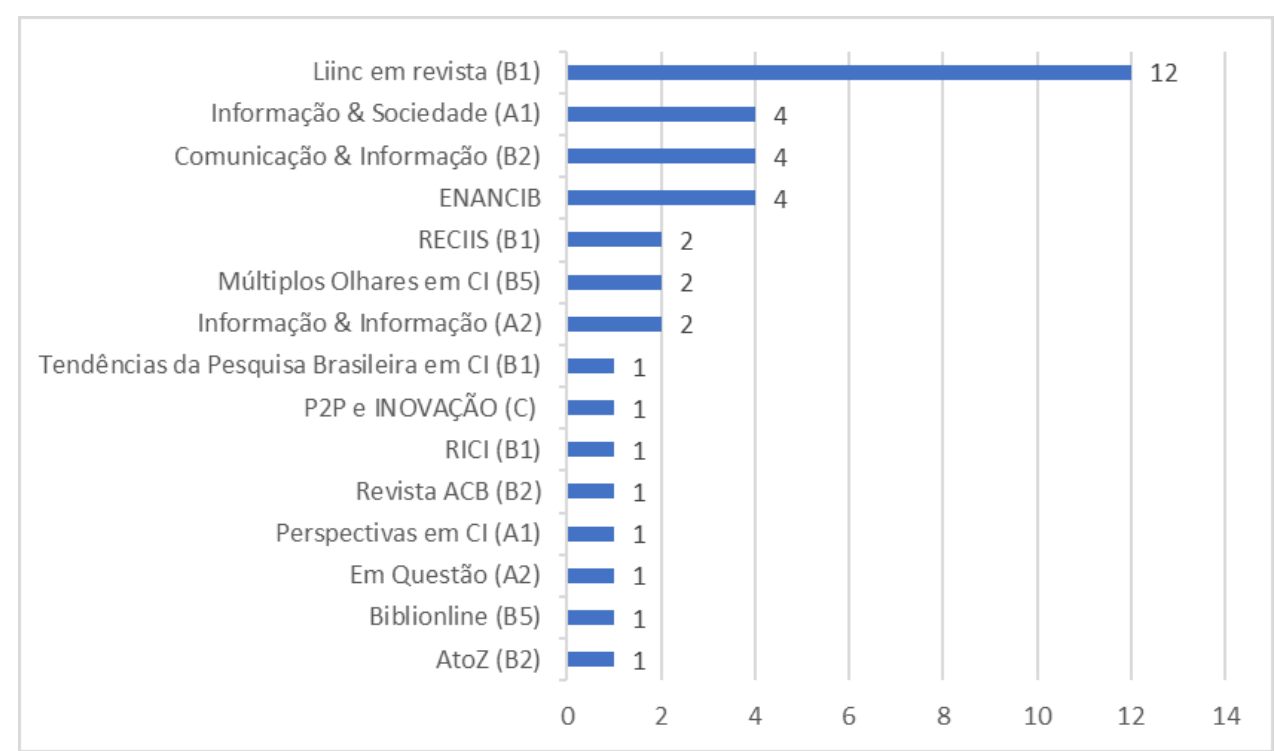

Fonte: Elaborado pelos autores.

Verifica-se no Gráfico 3 que o objeto analisado (mídias sociais e políticas) vem sendo discutido pela Ciência da Informação nos últimos dez anos, com exceção de 2009, em que não foi identificada nenhuma contribuição.

\section{Gráfico 3 - Produção científica/ano}

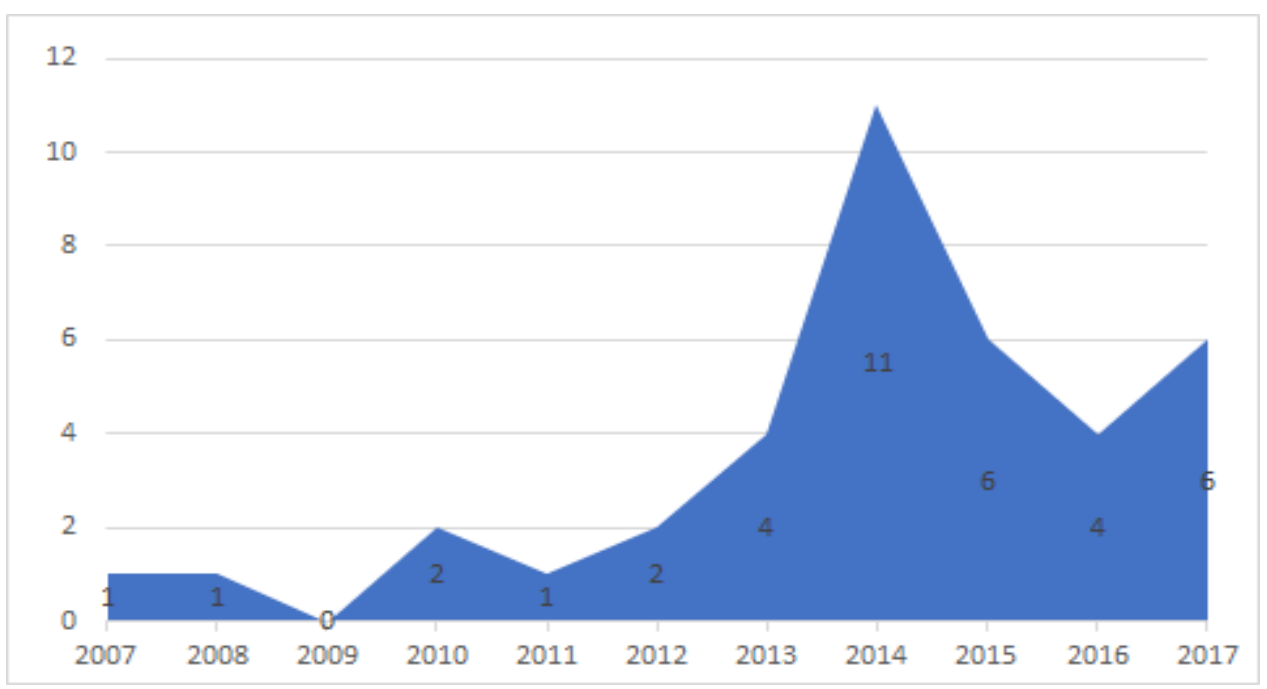

Fonte: Elaborado pelos autores.

Também é possível constatar um crescimento considerável a partir de 2013, com destaque para o ano de 2014, que apresentou o maior pico de produção. Dos doze artigos publicados nesse período, oito fizeram parte do fascículo temático da Liinc em Revista (v. 10, n. 1), cujo objetivo era debater "as 
diversas visões das jornadas de junho 2013 e seus possíveis desdobramentos, a partir das novas dinâmicas cognitivas, comunicativas e informacionais" (MACIEL; ALBAGLI, 2014, p. 1), apresentando relação direta com o objeto de nosso estudo.

\subsection{ANÁlISE do CONTEÚdo}

A partir da categorização da produção científica selecionada, tornou-se possível examinar o interesse da Ciência da Informação por temas relacionados ao domínio analisado e elencar os fatos que marcaram a história no Brasil e no mundo com o que a área tem produzido nos últimos dez anos, descrição delineada pelas categorias de análise - destacadas, nesta seção, em itálico -, quando os objetos deste estudo se imbricam.

Os primeiros estudos sobre mídias sociais e políticas na $\mathrm{Cl}$ abordaram: a) as contribuições dos profissionais da informação no processo de inclusão social, a partir de três desafios: as redes sociais on-line, a educação a distância e a ação cultural (RIBAS; ZIVIANI, 2007); e b) a responsabilidade social sob uma perspectiva ética, no contexto da extinta mídia social Orkut (BEZERRA; ARAÚJO, 2008) (Figura 1).

Em 2010, enquanto na América do Norte a ex-militar Chelsea Manning e o fundador do WikiLeaks, Julian Assange, tornavam públicas informações secretas sobre o governo americano e, na América Central, os problemas sociais do Haiti se agravavam com um terremoto de magnitude 7 , discutiam-se na $\mathrm{Cl}$ a relevância dos estudos das redes sociais nos processos de produção, comunicação e apropriação da informação (MARTELETO, 2010) e, ainda, as dimensões do Twitter e o papel da internet na mobilização dos usuários, apontados como a principal via de conexão do Haiti com o mundo, durante o sismo de 2010 (LIMA, 2010) (Figura 1).

Os recursos da internet também contribuíram na propagação do movimento social conhecido como Primavera Árabe, que iniciou no Oriente Médio e no norte da África, em 2011. Nesse mesmo ano, para garantir a efetividade do acesso a todas as informações produzidas e custodiadas pelo poder público, o governo brasileiro promulgou a Lei de Acesso à Informação 
(LAI) (Lei no 12.527/2011) (BRASIL, 2011), sem nenhuma menção explícita às mídias sociais, e na $\mathrm{Cl}$ as discussões voltavam-se para o uso do Orkut pela população sob uma perspectiva ética e filosófica (BEZERRA; ARAÚJO, 2011) (Figura 1). Implicitamente, as mídias sociais estão contempladas na LAl que especifica o uso de meios de comunicação viabilizados pela tecnologia da informação como uma de suas diretrizes para assegurar o direito de acesso à informação.

No ano em que uma das maiores mídias sociais do mundo, o Facebook, em 2012, tornava-se uma empresa de capital aberto e adquiria o aplicativo/serviço de fotos Instagram, pesquisadores da $\mathrm{Cl}$ refletiam sobre as contribuições da mediação nas mídias sociais em prol do ativismo político no segmento ambiental (Greenpeace), como uma forma de mobilização social (MORIGI; KREBS, 2012), e analisavam além da LAI, publicada no ano anterior, os movimentos Open Access e Open Data e a transparência pública no âmbito da saúde (CORDEIRO et al., 2012) (Figura 1).

Tal como Manning e Assange, em 2013, o ex-agente da inteligência norteamericana, Edward Snowden, foi acusado de espionagem por vazamento de dados sigilosos de segurança dos Estados Unidos. No mesmo ano, a exemplo da Primavera Árabe, o Brasil ficou marcado por uma série de protestos e manifestações de cunho econômico, social e político. De modo pontual, pesquisas na $\mathrm{Cl}$ analisaram o comportamento dos usuários e o significado das manifestações de junho de 2013 nas páginas do Facebook (SILVA, 2013); enquanto outras se preocupavam com o grau de exposição dos usuários nas mídias sociais, recomendando a implantação de políticas de segurança da informação (SILVA; ARAÚJO; AZEVEDO, 2013a, 2013b). Identificou-se também a preocupação com a elaboração de políticas institucionais e de projetos de mídias sociais para aprimorar a comunicação nas instituições de ensino superior do país (CORGOSINHO; MONTEIRO, 2013) (Figura 1). 
Figura 1 - Produção por ano/categoria

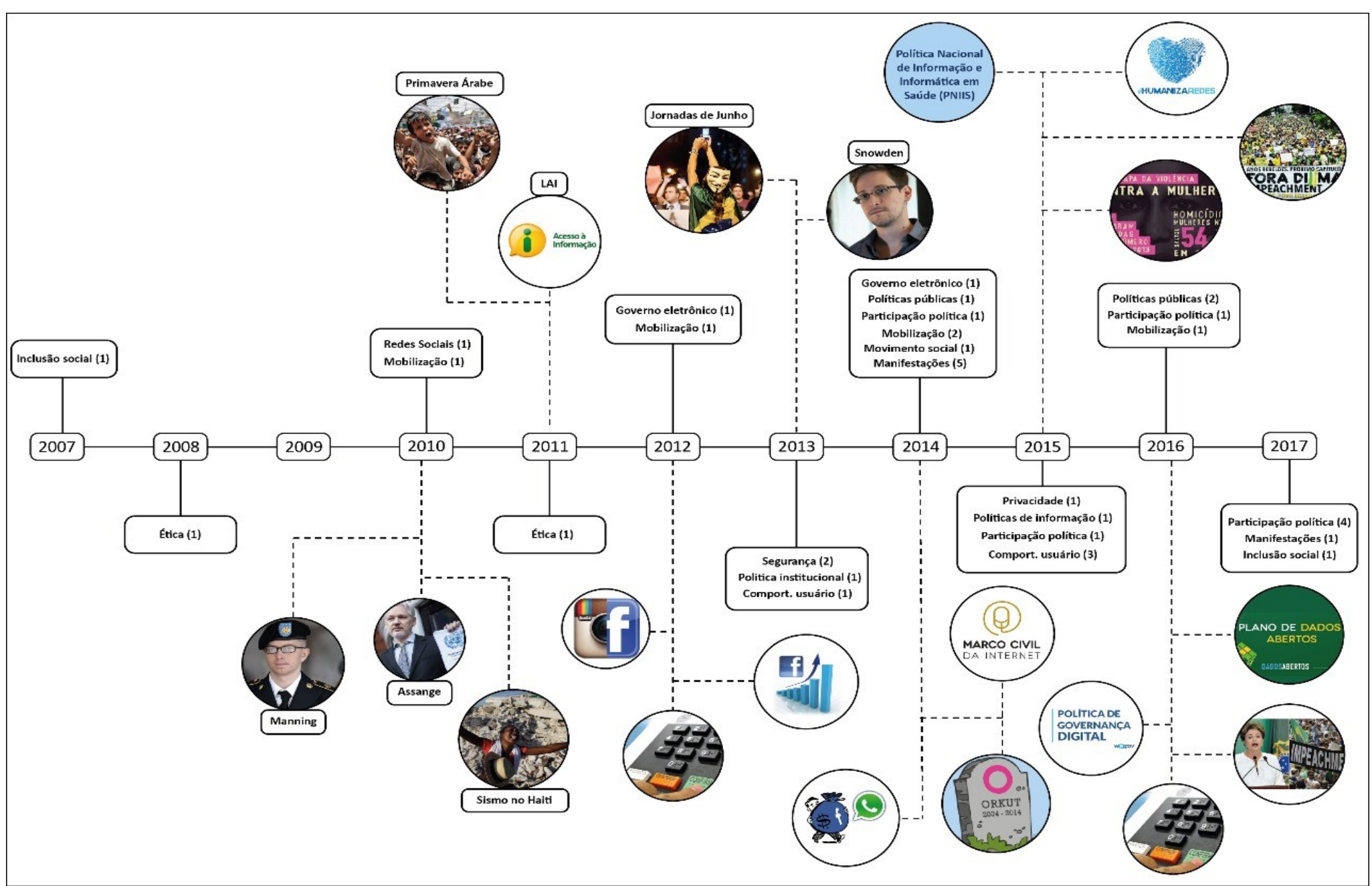

Fonte: Elaborada pelos autores. 
O ano de 2014 foi marcado por dois grandes anúncios de impacto no mundo tecnológico: a extinção da mídia social Orkut e a transação bilionária para aquisição do WhatsApp pelo Facebook. No contexto político brasileiro, além de ter sido um ano eleitoral, o uso da internet foi regulamentado pelo Marco Civil da Internet (Lei n 12.965/2014) (BRASIL, 2014), sem nenhuma menção direta às mídias sociais, a exemplo da LAl. De modo subjacente, as mídias sociais podem ser consideradas como um dos múltiplos canais de acesso para prestação dos serviços públicos de atendimento ao cidadão de forma integrada, conforme apontado em uma das diretrizes do Marco Civil para atuação do poder público no desenvolvimento da internet no Brasil. Na Ciência da Informação, 2014 foi o ano com o maior volume de produção no domínio analisado, apresentando estudos voltados para a) a participação político-partidária no Twitter, por meio das campanhas eleitorais (ARAÚJO, 2014); b) a investigação dos conteúdos relacionados à saúde e aos serviços de informação do governo veiculados no Facebook, Orkut e Twitter (SAMPAIO et al., 2014); e c) a análise da plataforma Observatório Participativo da Juventude, lançada após a participação massiva dos jovens nas manifestações de 2013 (ROTHBERG; LUVIZOTTO; VANZINI, 2014) (Figura 1).

No entanto, em 2014, a maior concentração das discussões na $\mathrm{Cl}$ focaram-se no papel/contribuições das mídias sociais e das tecnologias móveis de comunicação para a organização de movimentos sociais, mobilização e disseminação de reivindicações que incluíam uma diversidade de temas, como redução de taxas, violência, má qualidade dos serviços públicos, preservação patrimonial, corrupção política, dentre outros (BRIGNOL, 2014; HENRIQUES, 2014; ALBERNAZ; REIS, 2014; SANTOS, 2014; SANTOS; SILVA SOBRINHO, 2014; SOUZA; LIMA, 2014). Também foram identificados estudos que se preocupavam com a apropriação das Tecnologias da Informação e Comunicação (TIC) pelos jovens nas manifestações e ações de protestos (PRETTO, 2014) e a incapacidade dessas tecnologias em promover as transformações políticas prometidas (PEIXOTO, 2014) (Figura 1).

Em 2015, o governo federal brasileiro disponibilizou uma ouvidoria on-line, denominada Humaniza Redes, para defesa contra violações dos direitos 
humanos ocorridas na internet e fora dela, com uma forte atuação em diversas mídias sociais (Facebook, Twitter, Instagram e WhatsApp), visando ao combate à discriminação e ao preconceito. No mesmo ano, diversos membros da sociedade civil, e representantes de órgãos públicos e entidades privadas, motivados por eventos mundiais em prol do combate à violência contra a mulher com apoio das Nações Unidas, publicaram o Mapa da violência 2015: homicídio de mulheres no Brasil. Por sua vez, o Ministério da Saúde instituiu a Política Nacional de Informação e Informática em Saúde (PNIIS) (BRASIL, 2016c) que, apesar de não citar explicitamente as mídias sociais, apontou a implementação e promoção dos usos das TIC como umas de suas diretrizes; e no contexto político, o ano de 2015 foi marcado por protestos massivos contra o governo Dilma Rousseff.

$\mathrm{Na}$ Ciência da Informação, enquanto uns pesquisadores discutiram a democratização do acesso à informação da área da saúde enquanto política de informação, a partir de uma avaliação da fanpage do Ministério da Saúde (MOREIRA; PINHEIRO, 2015), outros se preocuparam com o papel das imagens no Instagram e no Facebook como fontes de dados, com foco na privacidade, e concluíram que as políticas dessas mídias sociais e dos usuários ainda eram vagas ou pouco claras (ASSUMPÇÃO; SANT'ANA, 2015). No âmbito político, alguns pesquisadores investigaram os recursos informacionais - incluindo as mídias sociais -, aplicados na condução das eleições brasileiras ao longo dos sufrágios, com enfoque na participação política (SOUZA; TOUTAIN, 2015); já outros analisaram as reações divergentes dos usuários do Facebook e do Twitter diante de postagens que contrapunham suas posições políticas durante as eleições de 2014 (MENDONÇA JÚNIOR; RODRIGUES; TAVARES, 2015). Também na perspectiva do comportamento dos usuários nas mídias sociais, pesquisadores apontaram, curiosamente, que muitos universitários buscam a internet e o Facebook como fonte para confirmar informações políticas extraídas de outras fontes (BRITO et al., 2015); e outros, com foco no discurso de ódio nas mídias sociais, analisaram as práticas informacionais no Facebook do Humaniza Redes, disponibilizado em 2015, ratificando a relevância do projeto do governo federal no fortalecimento da dimensão cidadã em respeito às diferenças 
(MORIGI et al., 2015) (Figura 1).

Em meio às manifestações contra e a favor ao impeachment de Dilma Rousseff, o cenário político brasileiro, em 2016, foi marcado pelo impedimento do governo da primeira Presidente mulher do Brasil. Nesse ano, além de eleições municipais, também foram instituídas: a) a Política de Governança Digital no âmbito dos órgãos e entidades da administração pública federal (Decreto $\mathrm{n}^{\circ}$ 8.638)(BRASIL, 2016a) - a partir da qual foi criada a Estratégia de Governança Digital (EGD): 2016-2019; e b) a Política de Dados Abertos do Poder Executivo Federal (Decreto $n^{\circ}$ 8.777) (BRASIL, 2016b), que deu origem à nova versão do Plano de Dados Abertos (PDA) (BRASIL, 2017) do Ministério do Planejamento, ambos elaborados em consonância com a LAl, dentre outros documentos afins. A EGD aponta o portal Participa.br - uma plataforma integrada com as principais mídias sociais, desenvolvida para captar contribuições da sociedade na elaboração de políticas públicas - como uma de suas iniciativas de acesso à informação voltadas à participação social (OE.05) (BRASIL, 2018). As mídias sociais - canais de comunicação e participação - também são elementos que devem compor um PDA, documento que orienta sobre as ações de implementação e promoção da abertura de dados nas organizações públicas (BRASIL, 2016d), conforme recomendação do Ministério do Planejamento.

Um ano depois da publicação do Mapa da violência 2015 sobre feminicídio, pesquisadores na $\mathrm{Cl}$ investigaram movimentos sociais de mobilização das mulheres no Twitter, a partir da hashtag \#primeiroassedio (ALMEIDA; TERRA; SANTINI, 2017). Por outro lado, as manifestações políticas de 2016 contra a presidente da República Dilma Rousseff serviram de cenário para o estudo dos padrões de etiquetagem (indexação) das imagens e fotografias no Flickr e Instagram pelos usuários, com foco na participação política (NOBREGA; MANINI, 2016, p. 73). Outros estudos analisaram o relacionamento e a contribuição das redes sociotécnicas na gestão de políticas públicas, com destaque para a relevância do ciberespaço na criação de redes sociais políticas (JESUS; SIMEÃO; MARTINS, 2016) e o processo de elaboração e discussão do Marco Civil da Internet, aprovado em 2014, com ênfase no estudo do ativismo em benefício dos direitos na internet, que permitiu diagnosticar a forma de 
mobilização na esfera governamental e fora dela, como nas mídias sociais (RADOMSKY; SOLAGNA, 2016) (Figura 1).

As produções científicas da Ciência da Informação no domínio analisado, em 2017, sofreram influência de eventos de impacto na sociedade brasileira, ocorridos entre 2013 e 2016, relacionados a: a) participação política, como as eleições e os protestos nacionais contra o governo Dilma e pela perda de seu cargo de Presidente da República; b) manifestações de 2013; e c) inclusão social por meio da participação cidadã. Ao analisar os sentimentos dos usuários nas mensagens postadas durante momentos distintos do impedimento político da então presidente Dilma Rousseff, pesquisadores concluíram que a "trolagem ofensiva" permeia o debate construído, evidenciando o predomínio de sentimentos de raiva, ansiedade e medo (MALINI; CIARELLI; MEDEIROS, 2017, p. 323). Em pesquisas referentes ao pleito eleitoral, um estudo identificou que a maior parte das postagens no Twitter sobre as eleições de 2014, para o governo de Alagoas, referiam-se à adesão de cidadãos à campanha, com parcas interações duradouras e reciprocidade, demonstrando que a ausência de interação efetiva entre candidato e eleitorado não é, necessariamente, consequência da falta de interesse dos cidadãos (ARAÚJO, 2017); em outra mídia social, pesquisadores diagnosticaram que, embora a maior parte das postagens no Facebook realizadas por um candidato à prefeitura de Maceió (AL), durante as eleições de 2016, estivesse relacionada à agenda da candidatura, a agradecimentos e cumprimentos de propostas de governo, a maior interação com eleitores se deu em postagens de cunho pessoal (ARAÚJO; SANTOS; BENTO, 2017). Ainda nesse contexto, a partir da análise de comentários postados também no Facebook, pesquisadores categorizaram o conteúdo de participação política por meio da triangulação metodológica na aplicação da Grounded Theory, como proposta para o desenvolvimento de esquema de classificação de conteúdo nesse segmento (ARAÚJO; TRAVIESORODRIGUEZ; SANTOS, 2017).

As manifestações de 2013 que deixaram como legado a possibilidade de o cidadão se organizar e fazer política por meio de dispositivos móveis também foram objeto de estudo em 2017. Pesquisadores analisaram o perfil de 
participantes das manifestações e o uso das tecnologias de comunicação, concluindo que essa atividade política se caracterizou pela formação de grupos pequenos e flexíveis e que tecnologias de comunicação instantânea, como Whatsapp e/ou Telegram, tiveram papel mais significativo que as mídias sociais no bojo do movimento social (PERALVA; FIGEAC; PATON, 2017). Dez anos depois de a temática da inclusão social ter sido discutida no domínio analisado, destaca-se o estudo que buscou compreender os impactos sociais da apropriação da internet por um líder comunitário da região Sul do Brasil, culminando com a conclusão de que o Facebook se tornou uma ferramenta política, mesmo apontando a arena privada como o condicionante da participação cidadã (ROSO; SILVA, 2017) (Figura 1).

\section{CONSIDERAÇÕES FINAIS}

O domínio mídias sociais e políticas passou a fazer parte das discussões dos pesquisadores da Ciência da Informação, desde 2007, atingindo o seu ápice em 2014, quando foram tratados temas como governo eletrônico, políticas públicas, movimento social, participação política, manifestações e mobilização. Sublinha-se ainda que esses três últimos foram os assuntos mais discutidos em todo o corpus de análise. Dentre os principais canais de comunicação científica da área, as questões relacionadas às mídias sociais no âmbito político têm sido comunicadas, com maior ênfase, em: Liinc em Revista, Informação \& Sociedade, Comunicação \& Informação e nos grupos de trabalho do Enancib.

Apesar de ser uma temática emergente, é possível afirmar que a Ciência da Informação já conta com uma elite de pesquisa representativa (17\%) no domínio analisado, com destaque para Regina Marteleto, Pierre Lévy, Raphael Capurro, Ronaldo Araújo, Wagner Araújo e Birger Hjørland. Confrontando os autores que citam com os mais citados, percebeu-se o estágio inicial de desenvolvimento de uma comunidade epistêmica, formada por Regina Marteleto, Fábio Malini e Wagner Araújo.

Quanto ao conteúdo discutido nos documentos analisados, ressalta-se a atenção dada pela área aos movimentos políticos brasileiros de 2013, em virtude da participação dos usuários das mídias sociais na organização de reuniões e 
discussões, bem como do fenômeno informacional oriundo do entrelaçamento entre o uso de TIC e tecnologias móveis, produção, disseminação e uso da informação, característicos do processo de mobilização social. De acordo com Castells (2008), as pessoas se mobilizam quando alguma coisa as afeta pessoalmente, seja em situações ocasionadas por desastres naturais, como observado em 2010, com o sismo do Haiti; seja quanto a causas ambientais defendidas por organizações como o Greenpeace; seja devido a questões sociais como o combate à violência contra a mulher, dentre outras. Para Castells (2008), a sensação de medo, pauta fundamental da sociedade, é superada pela indignação, o que motiva o indivíduo a comprometer-se na construção de um mundo melhor. Nesse contexto, as mídias sociais são ferramentas fundamentais para consolidar a ação política da mobilização ou como fonte propulsora ou disseminadora de informações sobre o movimento social.

Observou-se, ademais, que o interesse pelo tema da participação política cresceu nos últimos anos, já que todas as produções científicas nesse contexto foram publicadas de 2014 e 2017, ininterruptamente. É importante salientar que o intervalo temporal assinalado abrigou uma série de manifestações e mobilizações políticas e político-partidárias, além de processos políticos e eleitorais, o que culminou no recrudescimento do volume de pesquisas.

Dentre os desafios enfrentados durante a realização deste estudo, destaca-se a dificuldade de identificar a melhor categoria para representar determinado conteúdo, uma vez que muitos trabalhos se inserem em mais de uma categoria, principalmente aqueles categorizados em comportamento do usuário, provavelmente devido a sua ampla extensão de domínio, de caráter mais genérico. Um desses trabalhos, por exemplo, também poderia ter sido incluído na categoria manifestações, por abordar a efervescência política nas manifestações de 2013 por meio da mobilização pelas mídias sociais. Outro caso semelhante é um trabalho categorizado em mobilização e que também poderia ter sido classificado em Direitos humanos, por tratar do combate ao ódio nas mídias sociais. No entanto, o termo Direitos humanos, embora contemplado no Tesauro do IBICT, não foi elencado neste estudo.

Apesar de o Tesauro apresentar categorias consonantes com o princípio 
do exercício da influência sobre as decisões de interesse comum, não foi identificado algum conjunto categórico que permitisse a demarcação objetiva do conceito de participação política na $\mathrm{Cl}$. Diferentemente da categoria participação política, o termo mobilização, não identificado no Tesauro, transcende o caráter político-partidário, embora se mantenha convergente com princípios políticos, éticos, cidadãos, e de participação democrática. Para suprir a lacuna de vocabulário controlado capaz de garantir a cobertura do contexto analisado, como os exemplos acima citados, foram criadas categorias de análise, denominadas de vocabulário livre, representando não necessariamente produtos e serviços como apontado pelo Tesauro do IBICT, mas também fenômenos recorrentes e característicos deste novo milênio. Corroborando as ideias de Pinheiro e Ferrez (2014) - quando discutiram a complexidade da abordagem epistêmica adotada para a elaboração do Tesauro do IBICT -, como a Ciência da Informação no Brasil se preocupa mais com as questões teóricas, sociais e culturais, espera-se que este trabalho possa contribuir efetivamente no delineamento temático da área, acompanhando sua evolução terminológica e seu âmbito de aplicação.

Nos últimos dez anos observou-se um crescimento considerável da produção científica da Ciência da Informação na imbricação dos campos informacional, tecnológico e político, dada sua complexidade e relevância. Recentes fenômenos sociais, como: a) o vazamento de dados de usuários do Facebook pela Cambridge Analytica, em 2018; b) o crescimento do uso da internet e da proporção de usuários brasileiros de internet, apesar da permanência das desigualdades por classe, apontado pela pesquisa TIC Domicílios 2017; c) as eleições 2018, no Brasil; d) as mudanças no algoritmo do Facebook, com menor relevância para fanpages, priorizando as relações entre pessoas e interações entre membros, prenunciando um processo de intensificação da coesão de laços; e e) o impacto do Plano de Dados Abertos do Poder Executivo Federal no aprimoramento da cultura de transparência - esses fenômenos sociais, dentre outros, oferecem um ambiente fértil para o desenvolvimento de pesquisas com foco na segurança da informação, na privacidade, em políticas públicas de informação, na ética, participação política, 
mobilização, nas mídias sociais etc., contribuindo com a consolidação da Ciência da Informação como campo científico.

\section{REFERÊNCIAS}

ACIOLI, S. Redes sociais e teoria social: revendo os fundamentos do conceito. Informação \& Informação, Londrina, v. 12, n. esp., p. 1-12, 2007. Disponível em: http://www.uel.br/revistas/uel/index.php/informacao/article/view/1784/1520. Acesso em: 25 fev. 2018.

ARAÚJO, E. Internet e redes sociais como ferramentas de mobilização. [S. l.: s. n.], jan. 2016. Material de apoio à Oficina Redes Sociais e Mobilização ministrada por Gustavo Gindre. Disponível em: http://www.mobilizadores.org.br/wp-content/uploads/2016/01/Cartilha-RedesSociais-e-Mobilizacao.pdf. Acesso em: 25 fev. 2018.

BRASIL. Ministério do Planejamento, Desenvolvimento e Gestão. Estratégia de Governança Digital: EGD. Transformação digital: cidadania e governo: 2016-2019. Brasília, DF: MP, maio 2018. Disponível em: https://www.governodigital.gov.br/EGD/documentos/revisao-da-estrategia-degovernanca-digital-2016-2019.pdf. Acesso em: 26 jun. 2018.

BRASIL. Ministério do Planejamento, Orçamento e Gestão. Manual para elaboração de Plano de dados abertos. Brasília, DF: MP, jul. 2016d. Nova versão: 2017. Disponível em: http://www.planejamento.gov.br/secretarias/upload/arquivo/governoaberto/copy_of_manual_elaboracao_plano_dados_abertos.pdf. Acesso em: 26 abr. 2018.

BRASIL. Decreto $n^{\circ} 8.638$ de 15 de Janeiro de 2016. Institui a Politica de Governança Digital no âmbito dos órgãos e das entidades da administração pública federal direta, autárquica e fundacional. Brasília: Presidência da República, 2016a. Disponível em:

http://www.planalto.gov.br/ccivil_03/_Ato2015-2018/2016/Decreto/D8638.htm. Acesso em: 26 dez. 2019.

BRASIL. Decreto ${ }^{\circ} 8777$ de 11 de maio de 2016. Institui a política de dados abertos do Poder Executivo federal. Brasília: Presidência da República, 2016b. Disponível em: http://www.planalto.gov.br/ccivil_03/_ato20152018/2016/decreto/D8777.htm. Acesso em: 26 dez. 2019.

BRASIL. Lei $n^{\circ} 12.527$ de 18 de novembro de 2011. Regula o acesso a informações previsto no inciso XXXIII do art. $5^{\circ}$, no inciso II do $\S 3^{\circ}$ do art. $37 \mathrm{e}$ no $\S 2^{\circ}$ do art. 216 da Constituição Federal; altera a Lei $n^{\circ} 8.112$, de 11 de dezembro de 1990; revoga a Lei $n^{\circ} 11.111$, de 5 de maio de 2005, e dispositivos da Lei $n^{\circ} 8.159$, de 8 de janeiro de 1991; e dá outras providências. Brasília: Presidência da República, 2011. Disponível: 
http://www.planalto.gov.br/ccivil_03/_ato2011-2014/2011/lei//12527.htm. Acesso em: 26 dez. 2019.

BRASIL. Lei $\mathbf{n}^{\circ} \mathbf{1 2 . 9 6 5}$ de 23 de abril de 2014. Estabelece princípios, garantias, direitos e deveres para o uso da Internet no Brasil. Brasília: Presidência da República, 2014. Disponível em: http://www.planalto.gov.br/ccivil_03/_ato2011-2014/2014/lei//12965.htm. Acesso em: 26 dez. 2019.

BRASIL. Política Nacional de Informação e Informática em Saúde. Ministério da Saúde. Brasília: Ministério da Saúde, 2016c. Disponível em: http://bvsms.saude.gov.br/bvs/publicacoes/politica_nacional_infor_informatica_ saude_2016.pdf. Acesso em: 26 dez. 2019.

CASTELLS, Manuel. Por que as pessoas se mobilizam? 2008. 1 vídeo (3 min. 4), son., col. Publicado no site Fronteras del Pensiamento. Disponível em: http://www.fronteiras.com/es/videos/por-que-as-pessoas-se-mobilizam. Acesso em: 25 mar. 2018.

FRANÇA, M. N.; CARVALHO, A. M. G. de; GRÁCIO, M. C. C. Presença da temática mídias sociais e bibliotecas na produção científica brasileira na Ciência da Informação: um estudo de análise de domínio. In: IRIGARY, F.; GROSSI, A.; MACHADO FILHO, F.; MORAES, O. de; VENTURA, M. (Orgs.). Audiovisual, cidades, mobilidade, cidadania, jornalismo, mídia e tecnologia. Rosário: UNR Editora: Editorial de la Universidad Nacional de Rosário, 2018. p. 344-367. Disponível em:

http://docs.wixstatic.com/ugd/43846c_2e3f2973354349e798390617044d9e55.p df. Acesso em: 6 ago. 2018.

FUCHS, C. Mídias sociais e a esfera pública. Contracampo, Rio de Janeiro, v. 34, n. 3, p. 5-80, dez./mar. 2015.

KAPLAN, A. M.; HAENLEIN, M. Users of the world, unite! The challenges and opportunities of Social Media. Business Horizons, Indiana, v. 53, n. 1, p. 5968, 2010.

MACIEL, M. L.; ALBAGLI, S. Editorial: 10 anos da Liinc em Revista. Liinc em Revista, Rio de Janeiro, v. 10, n. 1, p. 1, maio 2014. Disponível em: http://revista.ibict.br/liinc/article/view/3540/3037. Acesso em: 25 fev. 2018.

MARTINO, L. M. S. Teoria das mídias digitais: linguagens, ambientes e redes. Rio de Janeiro: Vozes, 2014.

OLIVEIRA, J. A. de. Redes sociais e participação política na esfera pública. Revista Eptic, São Cristávão, v. 14, n. 1, p. 1-13, jan./abr. 2012.

PINHEIRO, L. V. R.; FERREZ, H. D. Tesauro brasileiro de Ciência da Informação. Rio de Janeiro: IBICT, 2014. 
SILVA, E. L. da; MENEZES, E. M. Metodologia da pesquisa e elaboração da dissertação. 4. ed. rev. e atual. Florianópolis: UFSC, 2005.

URBIZAGÁSTEGUI ALVARADO, R. Elitismo na literatura sobre a produtividade dos autores. Ciência da Informação, Brasília, DF, v. 38, n. 2, p. 69-79, maio/ago. 2009.

\section{AGRADECIMENTOS}

À Universidade Federal de Uberlândia pela concessão a Maira Nani França de afastamento para cursar estudos de Doutorado no PPGCI/UNESP (Marília, SP) e à Coordenação de Aperfeiçoamento de Pessoal de Nível Superior (Capes) pela concessão a Gabriel Henrique de Oliveira Lopes da Bolsa de Pesquisa para estudos de Mestrado no PPGCI/UNESP (Marília, SP).

\section{Apêndice A - Produção científica por categoria de análise}

\begin{tabular}{|c|c|}
\hline Redes sociais & $\begin{array}{l}\text { MARTELETO, R. M. Redes sociais, mediação e apropriação de informaçães: } \\
\text { situando campos, objetos e conceitos na pesquisa em ciência da informação. } \\
\text { Tendências da Pesquisa Brasileira em Ciência da Informação, Brasília, DF, v. 3, } \\
\text { n. 1, p. 27-46, jan./dez. 2010. Disponível em: } \\
\text { http://www.brapci.inf.br/index.php/article/download/13080. Acesso em: } 25 \text { fev. } 2018 \text {. }\end{array}$ \\
\hline $\begin{array}{l}\text { Ética na } \\
\text { informação }\end{array}$ & $\begin{array}{l}\text { BEZERRA, M. A. A.; ARAÚJO, E. A. de. Uma ética da informação para pensar o } \\
\text { Orkut: reflexões sobre a informação e a liberdade no contexto da Sociedade da } \\
\text { Informação. Informação \& Sociedade: Estudos, João Pessoa, v. 18, n. 2, p. 207- } \\
\text { 2018, maio/ago. 2008. Disponível em: } \\
\text { http://www.brapci.inf.br/index.php/article/download/39510. Acesso em: } 25 \text { fev. } 2018 . \\
\text { BEZERRA, M. A. A.; ARAÚJO, E. A. de. Reflexões epistemológicas no contexto do } \\
\text { Orkut: ética da informação, sociabilidade, liberdade e identidade. Perspectivas em } \\
\text { Ciência da Informação, Belo Horizonte, v. 16, n. 2, p. 50-66, jun./ago. 2011. } \\
\text { Disponível em: htttp://www.brapci.inf.br/index.php/article/download/17170. Acesso em: } \\
25 \text { fev. 2018. }\end{array}$ \\
\hline $\begin{array}{c}\text { Direito à } \\
\text { privacidade }\end{array}$ & $\begin{array}{l}\text { ASSUMPÇÃO, F. S.; SANT'ANA, R. C. G. Coleta de dados a partir de imagens: } \\
\text { considerações sobre a privacidade dos usuários em redes sociais. Em Questão, } \\
\text { Porto Alegre, v. 21, n. 2, p. 31-48, maio/ago. 2015. Disponível em: } \\
\text { http://www.brapci.inf.br/index.php/article/download/37753. Acesso em: } 25 \text { fev. } 2018 .\end{array}$ \\
\hline \multirow[b]{2}{*}{$\begin{array}{l}\text { Segurança da } \\
\text { informação }\end{array}$} & $\begin{array}{l}\text { SILVA, N. B. X.; ARAÚJO, W. J. de A.; AZEVEDO, P. M. de. Análise de informações } \\
\text { pessoais na web: métrica para identificar o grau de exposição da informação. In: } \\
\text { ENCONTRO NACIONAL DE PESQUISA EM CIÊNCIA DA INFORMAÇÃO, 14., } \\
\text { 2013, Florianópolis. Anais... [S.I.]: ANCIB, 2013a. p. 1-7. Disponível em: } \\
\text { htttp://www.brapci.inf.br/index.php/article/download/40332. Acesso em: } 25 \text { fev. } 2018 .\end{array}$ \\
\hline & $\begin{array}{l}\text { SILVA, N. B. X.; ARAÚJO, W. J. de A.; AZEVEDO, P. M. de. Engenharia social nas } \\
\text { redes sociais online: um estudo de caso sobre a exposição de informações pessoais } \\
\text { e a necessidade de estratégias de segurança da informação. RICl: Revista lbero- } \\
\text { Americana de Ciência da Informação., Brasilia, DF, v. } 6, \text { n. } 2 \text {, p. } 37-55 \text {, ago./dez. } \\
\text { 2013b. Disponível em: http://www.brapci.inf.br/index.php/article/download/57463. } \\
\text { Acesso em: } 25 \text { fev. } 2018 \text {. }\end{array}$ \\
\hline $\begin{array}{l}\text { Governo } \\
\text { eletrônico }\end{array}$ & $\begin{array}{l}\text { CORDEIRO, A.; MARTINS, C. S. F.; SANTOS, N. B. dos; RIBEIRO, R. V.; PETRA, T. } \\
\text { Governo eletrônico e redes sociais: informação, participação e interação. Revista } \\
\text { Eletrônica de Comunicação, Informação \& Inovação em Saúde, Rio de Janeiro, v. } \\
\text { 6, n. 2, jun. 2012. Disponível em: } \\
\text { http://www.brapci.inf.br/index.php/article/download/43298. Acesso em: } 25 \text { fev. } 2018 .\end{array}$ \\
\hline
\end{tabular}




\begin{tabular}{|c|c|}
\hline & $\begin{array}{l}\text { SAMPAIO, R. B.; SILVA, L. P.; ESTEVES, E. F. S.; MARTINS, W. de J. Proposta de } \\
\text { metodologia para análise de redes sociais aplicadas a sites de saúde. Revista } \\
\text { Eletrônica de Comunicação, Informação \& Inovação em Saúde, Rio de Janeiro, v. } \\
\text { 8, n. 1, p. 9-19, mar. 2014. Disponível em: } \\
\text { http://www.brapci.inf.br/index.php/article/download/43179. Acesso em: } 25 \text { fev. } 2018 .\end{array}$ \\
\hline \multirow{3}{*}{ Política públicas } & $\begin{array}{l}\text { ROTHBERG, D.; LUVIZOTTO, C. K.; VANZINI, K. V. da S. As revoltas e seu impacto } \\
\text { sobre a comunicação pública: o potencial do Observatório Participativo da Juventude. } \\
\text { Liinc em Revista, Rio de Janeiro, v. 10, n. 1, p. 227-240, maio 2014. Disponível em: } \\
\text { http://www.brapci.inf.br/index.php/article/download/50630. Acesso em: } 25 \text { fev. 2018. }\end{array}$ \\
\hline & $\begin{array}{l}\text { JESUS, M. S. de; SIMEÃO, E. L. M. S.; MARTINS, W. de J. Rede sociotécnica na } \\
\text { governança de políticas públicas: o contexto da comunicação extensiva. Revista } \\
\text { ACB: Biblioteconomia em Santa Catarina, Florianópolis, v. 21, n. 1, p. 17-26, } \\
\text { dez./mar. 2016. Disponível em: } \\
\text { http://www.brapci.inf.br/index.php/article/download/45054. Acesso em: } 25 \text { fev. } 2018 .\end{array}$ \\
\hline & $\begin{array}{l}\text { RADOMSKY, G.; SOLAGNA, F. Marco civil da internet: abrindo a caixa-preta da } \\
\text { agenda de uma política pública. Liinc em Revista, Rio de Janeiro, v. 12, n. 1, p. 57- } \\
\text { 71, maio 2016. Disponível em: } \\
\text { http://www.brapci.inf.br/index.php/article/download/49343. Acesso em: } 25 \text { fev. } 2018 .\end{array}$ \\
\hline $\begin{array}{l}\text { Políticas de } \\
\text { informaçãoo }\end{array}$ & $\begin{array}{l}\text { MOREIRA, F. M.; PINHEIRO, M. M. K. Ministério da Saúde no Facebook: um estudo } \\
\text { de caso da política de informação. Informação \& Informação, Londrina, v. 20, n. 3, } \\
\text { p. 147-174, set./dez. 2015. Disponível em: } \\
\text { http://www.brapci.inf.br/index.php/article/download/43048. Acesso em: } 25 \text { fev. } 2018 .\end{array}$ \\
\hline $\begin{array}{c}\text { Política } \\
\text { institucional }\end{array}$ & $\begin{array}{l}\text { CORGOSINHO, R. J. M.; MONTEIRO, S. D. Elementos essenciais para implantação } \\
\text { de projetos de mídias sociais em Instituições de Ensino Superior. In: ENCONTRO } \\
\text { NACIONAL DE PESQUISA EM CIÊNCIA DA INFORMAÇÃO, 14., 2013, } \\
\text { Florianópolis. Anais... [S.I.]: ANCIB, 2013. p. 1-16. Disponivel em: } \\
\text { http://www.brapci.inf.br/index.php/article/download/40332. Acesso em: } 25 \text { fev. } 2018 .\end{array}$ \\
\hline \multirow{6}{*}{$\begin{array}{l}\text { Participação } \\
\text { política }\end{array}$} & $\begin{array}{l}\text { ARAÚJO, R. F. de. Aspectos teórico-metodológicos para análise de campanhas } \\
\text { eleitorais online no Twitter: do mapeamento das redes às conversações? Liinc em } \\
\text { Revista, Rio de Janeiro, v. 10, n. 2, p. 703-725, nov. 2014. Disponível em: } \\
\text { http://www.brapci.inf.br/index.php/article/download/50688. Acesso em: } 25 \text { fev. } 2018 .\end{array}$ \\
\hline & $\begin{array}{l}\text { SOUZA, I. C. de O.; TOUTAIN, L. M. B. B. Produção, circulação e uso da informação } \\
\text { no desenvolvimento político eleitoral brasileiro. In: ENCONTRO NACIONAL DE } \\
\text { PESQUISA EM CIÊNCIA DA INFORMAÇÃO, 16., 2015, João Pessoa. Anais... [S.I.]: } \\
\text { ANCIB, 2015. p. 1-18. Disponível em: } \\
\text { http://www.brapci.inf.br/index.php/article/download/52391. Acesso em: } 25 \text { fev. } 2018 .\end{array}$ \\
\hline & $\begin{array}{l}\text { NOBREGA, I. de O. e; MANINI, M. P. \#Impeachment ou \#naovaitergolpe: uma } \\
\text { análise sobre a folksonomia na indexação de imagens fotográficas em redes sociais } \\
\text { da web 2.0. Biblionline, João Pessoa, v. 12, n. 4, 2016 p. 73-84, 2016. Disponível } \\
\text { em: http://wwww.brapci.inf.br/index.php/article/download/51990. Acesso em: } 25 \text { fev. } \\
2018 .\end{array}$ \\
\hline & $\begin{array}{l}\text { ARAÚJO, R. F. de; SANTOS, S. R. de O.; BENTO, J. M. Mediação da informação e } \\
\text { comunicação política no Facebook: desempenho do candidato Rui Palmeira à } \\
\text { Prefeitura de Maceió em 2016. AtoZ: Novas Práticas em Informação e } \\
\text { Conhecimento, Curitiba, v. 6, n. 1, p. 17-25, jan./jun. 2017. Disponível em: } \\
\text { http://www.brapci.inf.br/index.php/article/download/59184. Acesso em: } 25 \text { fev. } 2018 .\end{array}$ \\
\hline & $\begin{array}{l}\text { ARAÚJU, R. F. de; TRAVIESO-RODRIGUEZ, C.; SANTOS, S. R. de O. } \\
\text { Comunicação e participação política no Facebook: análise dos comentários em } \\
\text { páginas de parlamentares brasileiros. Informação \& Sociedade: Estudos, João } \\
\text { Pessoa, v. 27, n. 2, p. 279-290, maio/ago. 2017. Disponível em: } \\
\text { http://www.brapci.inf.br/index.php/article/download/57213. Acesso em: } 25 \text { fev. } 2018 .\end{array}$ \\
\hline & $\begin{array}{l}\text { ARAÚJO, R. F. de. O Twitter como dispositivo de mediação da informação em } \\
\text { períodos eleitorais: análise das eleições de } 2014 \text { em Alagoas. Informação \& } \\
\text { Informação, Londrina, v. 22, n. 2, p. 420-436, maio/ago. 2017. Disponível em: } \\
\text { http://www.brapci.inf.br/index.php/article/download/60394. Acesso em: } 17 \text { abr. } 2018 .\end{array}$ \\
\hline
\end{tabular}




\begin{tabular}{|c|c|}
\hline & $\begin{array}{l}\text { MALINI, F.; CIARELLI, P.; MEDEIROS, J. O sentimento político em rede sociais: big } \\
\text { data, algoritmos e as emoções nos tweets sobre o impeachment de Dilma Rousseff. } \\
\text { Liinc em Revista, Rio de Janeiro, v. 13, n. 2, p. 323-342, nov. 2017. Disponível em: } \\
\text { http://www.brapci.inf.br/index.php/article/download/59465. Acesso em: } 25 \text { fev. } 2018 .\end{array}$ \\
\hline \multirow{5}{*}{ Mobilização } & $\begin{array}{l}\text { LIMA, L. S. H. A teoria weberiana e suas manifestações no jornalismo: Twitter e o } \\
\text { caso Haiti. Comunicação \& Informação, Goiânia, v. 13, n. 1, p. 93-101, jan.jul. } \\
\text { 2010. Disponível em: http://www.brapci.inf.br/index.php/article/download/50346. } \\
\text { Acesso em: } 25 \text { fev. } 2018 .\end{array}$ \\
\hline & $\begin{array}{l}\text { MORIGI, V. J.; KREBS, L. M. Redes de mobilização social: as práticas informacionais } \\
\text { do Greenpeace. Informação \& Sociedade: Estudos, João Pessoa, v. 22, n. 3, p. } \\
\text { 133-142, set./dez. 2012. Disponível em: } \\
\text { https://www.lume.ufrgs. br/bitstream/handle/10183/173214/000870911.pdf?sequence= } \\
\text { 1. Acesso em: } 25 \text { fev. } 2018 \text {. }\end{array}$ \\
\hline & $\begin{array}{l}\text { BRIGNOL, L. D. \#Vem pra rua_Santa Maria: movimentos sociais em rede, } \\
\text { mobilização social e usos do Facebook em ações de protesto. Liinc em Revista, Rio } \\
\text { de Janeiro, v. 10, n. 1, p. 258-272, maio 2014. Disponível em: } \\
\text { http://revista.ibict.br/liinc/article/view/3521/3031. Acesso em: } 25 \text { fev. } 2018 .\end{array}$ \\
\hline & $\begin{array}{l}\text { ALBERNAZ, R. O.; REIS, M. G. dos. O processo de patrimonialização e a } \\
\text { cibercultura: mobilização no ciberespaço através de grupos na rede social Facebook. } \\
\text { Comunicação \& Informação, Goiânia, v. 17, n. 1, p. 21-35, jul./dez. 2014. Disponível } \\
\text { em: http://www.brapci.inf.br/index.php/article/download/53555. Acesso em: } 25 \text { fev. } \\
2018 .\end{array}$ \\
\hline & $\begin{array}{l}\text { ALMEIDA, A. R. D. de; TERRA, C.; SANTINI, R. M. Feminismo 2.0: a mobilização } \\
\text { das mulheres no Brasil contra o assédio sexual através das mídias sociais } \\
\text { (\#primeiroassedio). Revista P2P e INOVAÇÃO, Rio de Janeiro, v. 3, n. 1, set./mar. } \\
\text { 2017. Disponível em: http://www.brapci.inf.br/index.php/article/download/46257. } \\
\text { Acesso em: } 25 \text { fev. } 2018 .\end{array}$ \\
\hline $\begin{array}{l}\text { Movimento } \\
\text { social }\end{array}$ & $\begin{array}{l}\text { SANTOS, A. L. F. dos; SILVA SOBRINHO, S. da. Mídias e conflitos: as diversas } \\
\text { facetas da informação. Observando Cairo, Egito. Liinc em Revista, Rio de Janeiro, v. } \\
\text { 10, n. 1, p. 362-376, maio 2014. Disponível em: } \\
\text { http://www.brapci.inf.br/index.php/article/download/36555. Acesso em: } 25 \text { fev. } 2018 .\end{array}$ \\
\hline \multirow{6}{*}{ Manifestações } & $\begin{array}{l}\text { HENRIQUES, S. As manifestações no Brasil e a formação de redes sociais móveis } \\
\text { no contexto da sociedade atual. Liinc em Revista, Rio de Janeiro, v. 10, n.1, p. 211- } \\
\text { 226, maio 2014. Disponível em: } \\
\text { http://www.brapci.inf.br/index.php/article/download/50732. Acesso em: } 25 \text { fev. } 2018 .\end{array}$ \\
\hline & $\begin{array}{l}\text { PRETTO, N. De L. Redes sociais e educação: o que quer a geração alt+tab nas } \\
\text { ruas? Liinc em Revista, Rio de Janeiro, v. 10, n. 1, p. 344-350, maio } 2014 \text {. } \\
\text { Disponível em: http://www.brapci.inf.br/index.php/article/download/50731. Acesso em: } \\
25 \text { fev. 2018. }\end{array}$ \\
\hline & $\begin{array}{l}\text { SANTOS, E. H. Crise de representação política no Brasil e os protestos de junho de } \\
\text { 2013. Liinc em Revista, Rio de Janeiro, v. 10, n. 1, p. 86-95, maio 2014. Disponível } \\
\text { em: http://www.brapci.inf.br/index.php/article/download/50607. Acesso em: } 25 \text { fev. } \\
2018 .\end{array}$ \\
\hline & $\begin{array}{l}\text { PEIXOTO, O. M. 2013, o ano em que a geração y debutou nas ruas como } \\
\text { consumidora. Liinc em Revista, Rio de Janeiro, v. 10, n. 1, p. 138-148, maio } 2014 . \\
\text { Disponível em: http://www.brapci.inf.br/index.php/article/download/50616. Acesso em: } \\
25 \text { fev. 2018. }\end{array}$ \\
\hline & $\begin{array}{l}\text { SOUZA, H. da C. A. de; LIMA, M. R. D. V. de. A democracia em crise: o olhar da } \\
\text { comunicação sobre as manifestações de rua no Brasil em 2013. Liinc em Revista, } \\
\text { Rio de Janeiro, v. 10, n. 1, p. 96-108, maio 2014. Disponível em: } \\
\text { http://www.brapci.inf.br/index.php/article/download/50723. Acesso em: } 25 \text { fev. } 2018 .\end{array}$ \\
\hline & $\begin{array}{l}\text { PERALVA, A.; FIGEAC, J.; PATON, N. Resta algo de 2013? Liinc em Revista, Rio } \\
\text { de Janeiro, v. 13, n. 2, p. 381-400, nov. 2017. Disponível em: } \\
\text { http://www.brapci.inf.br/index.php/article/view/0000027928/309df951f17bdba67cc4ee } \\
\text { a4e9be0f5b. Acesso em: } 25 \text { fev. } 2018 .\end{array}$ \\
\hline $\begin{array}{l}\text { Comportamento } \\
\text { do usuário }\end{array}$ & $\begin{array}{l}\text { SILVA, R. B. da. Mídias sociais e política: as jornadas de junho no Facebook do PT. } \\
\text { Comunicação \& Informação, Goiânia, v. 16, n. 2, p. 53-71, jul./dez. 2013. Disponível }\end{array}$ \\
\hline
\end{tabular}




\begin{tabular}{|c|c|}
\hline & $\begin{array}{l}\text { em: http://www.brapci.inf.br/index.php/article/download/53576. Acesso em: } 25 \text { fev. } \\
2018 .\end{array}$ \\
\hline & $\begin{array}{l}\text { MENDONÇA JÚNIOR, F. M.; RODRIGUES, P. C. D.; TAVARES, W. M. } \\
\text { Comportamentos (extremos) dos usuários de redes sociais relativos ao tema política. } \\
\text { Múltiplos Olhares em Ciência da Informação, Belo Horizonte, v. 5, n. 2, out. } 2015 . \\
\text { Disponível em: http://www.brapci.inf.br/index.php/article/download/47234. Acesso em: } \\
25 \text { fev. } 2018 \text {. }\end{array}$ \\
\hline & $\begin{array}{l}\text { MORIGI, V. J.; MASSONI, L. F. H.; STUEBER, K.; MARINHO, A. C. de M. Práticas } \\
\text { informacionais do humaniza redes no Facebook: combatendo o discurso de ódio em } \\
\text { redes sociais. In: ENCONTRO NACIONAL DE PESQUISA EM CIÊNCIA DA } \\
\text { INFORMAÇÃO, 16., 2015, João Pessoa. Anais... [S. I.]: ANCIB, 2015. p. 1-18. } \\
\text { Disponível em: http://www.brapci.inf.br/index.php/article/download/43883. Acesso em: } \\
25 \text { fev. 2018. }\end{array}$ \\
\hline & $\begin{array}{l}\text { BRITO, F. T.; AGANETTE, K. P. de J.; SOBREIRA, F. R.; NONATO, R. A.; ANJOS, } \\
\text { P. F. dos; SOARES, F. M.; DUARTE, A. B. S. Processos de busca de informação } \\
\text { política dos estudantes de Graduação da UFMG: uma abordagem qualitativa. } \\
\text { Múltiplos Olhares em Ciência da Informação, Belo Horizonte, v. 5, n. 2, out. } 2015 . \\
\text { Disponível em: http://www.brapci.inf.br/index.php/article/download/47268. Acesso em: } \\
25 \text { fev. } 2018 \text {. }\end{array}$ \\
\hline \multirow[b]{2}{*}{ Inclusão social } & $\begin{array}{l}\text { RIBAS, C. S. da C.; ZIVIANI, P. O profissional da informação: rumos e desafios para } \\
\text { uma sociedade inclusiva. Informação \& Sociedade: Estudos, João Pessoa, v. 17, n. } \\
\text { 3, p. 47-57, set./dez. 2007. Disponível em: } \\
\text { http://www.brapci.inf.br/index.php/article/download/12684. Acesso em: } 25 \text { fev. } 2018 .\end{array}$ \\
\hline & $\begin{array}{l}\text { ROSO, A.; SILVA, S. R. da. Participação cidadã no contexto da internet: um estudo } \\
\text { sobre o uso de mília social por lideranças comunitárias na região centro-oeste do Rio } \\
\text { Grande do Sul, Brasil. Comunicação \& Informação, Goiânia, v. 17, n. 2, p. 92-114, } \\
\text { jan./jul. 2017. Disponível em: } \\
\text { http://www. brapci.inf.br/index.php/article/download/52911. Acesso em: } 25 \text { fev. } 2018 \text {. }\end{array}$ \\
\hline
\end{tabular}

\title{
PERSPECTIVE OF BRAZILIAN RESEARCH IN INFORMATION SCIENCE ON SOCIAL MEDIA AND POLITICS
}

\begin{abstract}
Introduction: In contemporaneity, political phenomena and social networks (ties) into social media allow us to reflect on how social actors connect to each other, to influence or to relate themselves in society. Objective: Identify Information Science researches contribution on Social Media and Politics topics, covering public policy and manifestation, or protests, or political participation. Methodology: To this end, scientific studies recovered were subjected to bibliometric and chronological content analysis, associating these listed researches to historical facts or current events. Results: The scientific documents have been produced since 2007 and presents an elite group of researchers and epistemic community in formation. The most productive year was 2014, with discussions about role of social media in organization of protest movements, manifestations, political participation, e-government and public campaigns, contributing to the thematic delineation of the area, monitoring of its evolution and its scope. Conclusions: In last ten years, Information Science researches on information, technological and political fields have increased, in its complexity and relevance.
\end{abstract}

Descriptors: Social networks. Social media. Information policies. Information Right. 
Access to public information.

\title{
PERSPECTIVA DE LAS INVESTIGACIONES EN CIENCIA DE LA INFORMACIÓN EN BRASIL SOBRE MEDIOS SOCIALES Y POLÍTICAS
}

\begin{abstract}
RESUMEN
Introducción: La comprensión de los fenómenos políticos y las redes sociales (interacciones) en los medios sociales permite reflexionar sobre formas en que los actores se conectan, influencian y se relacionan en la sociedad contemporánea. Objetivo: Identificar las contribuciones de las investigaciones de la Ciencia de la Información sobre Medios Sociales y Políticas, a partir de la concepción de política pública, hasta la acción social orientada hacia la política. Metodología: Los documentos recuperados fueron sometidos a análisis bibliométrico y cronológico del contenido asociado a hechos que marcaron historia en Brasil y en el mundo. Resultados: Las producciones científicas de la Ciencia de la Información en el dominio analizado han sido desarrolladas desde 2007, con una élite de investigadores y una comunidad epistémica en formación. El periodo de mayor productividad fue 2014, con discusiones sobre el rol de los medios sociales en la organización de movilizaciones, manifestaciones, participación política, gobierno electrónico y políticas públicas, contribuyendo para el delineamiento temático del área, acompañamiento de su evolución y de su ámbito de aplicación. Conclusiones: En los últimos diez años, se observó un crecimiento considerable de la producción científica de la Ciencia de la Información en la imbricación de los campos informacional, tecnológico y político, dada su complejidad y relevancia.
\end{abstract}

Descriptores: Redes sociales. Medios sociales. Políticas de información. Derecho a la información. Acceso a la información pública. 